\title{
Developmental staging models in bipolar disorder
}

Ives C Passos ${ }^{1,2}$, Karen Jansen ${ }^{1,3}$ and Flavio Kapczinski ${ }^{1,2^{*}}$

\begin{abstract}
The previous contribution of Duffy and colleagues suggests that a chain of behavioral events starting during childhood precedes the development of full-blown bipolar disorder. In this vein, the recent contribution of Keown-Stoneman and colleagues brings a new perspective to the study of prodromal symptoms of bipolar disorder.
\end{abstract}

Keywords: Bipolar disorder; Staging models; Prodromal symptoms

\section{Findings}

In 2010, Duffy et al. showed that subjects diagnosed with bipolar disorder (BD) followed a predictable sequence of prodromal symptoms (Duffy et al. 2010). Specifically, the majority of premorbid children developed prodromal symptoms including sleep and anxiety disturbances which evolved to minor depressive symptoms and sensitivity to stress during puberty (Duffy et al. 2010). Subsequently, in mid-adolescence, recurrent major depressive episodes occurred. Around 3 years later, conversion to $\mathrm{BD}$ took place with the emergence of hypomanic/manic episodes (Duffy et al. 2010) (Fig. 1). Duffy et al. also showed that combining familial risk with the presence of an anxiety disorder elevated the age-adjusted risk for a major mood disorder to over 80 \% (Duffy et al. 2010). This is an interesting finding, since whereas a positive family history of BD is the strongest risk factor for bipolar disorder (Lapalme et al. 1997), the majority of first-degree relatives of bipolar probands do not develop bipolar disorder (Rice et al. 1987). Of note, it also recognized that not all offspring go through all stages, rather once an individual joins the staging model, they progress from that point forward (i.e., may skip stage 1 and enter at stage 2 jumping from well to minor mood/adjustment disorders). Within this current issue, Keown-Stoneman and colleagues moved the field forward showing the estimated

\footnotetext{
* Correspondence: flavio.kapczinski@gmail.com

${ }^{1}$ UT Center of Excellence on Mood Disorder, Department of Psychiatry and Behavioral Sciences, The University of Texas Science Center at Houston, 1941 East Road, Houston, TX 77054, USA

${ }^{2}$ Bipolar Disorder Program and Laboratory of Molecular Psychiatry, Federal University of Rio Grande do Sul, Porto Alegre, RS, Brazil

Full list of author information is available at the end of the article
}

probability of patients being in each stage of the model previously described (Duffy et al. 2010).

Generally, staging models imply that natural history of the disorder moves through a predictable temporal progression, and provision of stage-appropriate treatment can modify such course. Some medical specialties such as cardiology and oncology have advanced in this field, developing strategies to prevent both the onset and the development of established disease. In the same way, bipolar disorder identified in the early stages may be less treatment refractory with a greater probability of response to monotherapy (Scott et al. 2006; Swann et al. 1999). Therefore, the contribution of developmental staging is really important since it provides the opportunity to intervene therapeutically in premorbid patients with bipolar disorder thus preventing a more pernicious course of illness.

In 2007, Berk et al. presented a staging model of the longitudinal course of bipolar disorder and the temporal impact of interventions (Berk et al. 2007). Subjects at stage 0 are those at increased risk of severe mood disorder (e.g., family history). Subjects with prodromal features of bipolar disorder were classified at stage 1, whereas those who had the first-episode threshold mood disorder were classified in stage 2 . Subjects at stage 3 were those with recurrent mood episodes, and subjects with persistent unremitting illness were classified at stage 4 . The model emphasizes early detection and algorithm appropriate intervention where possible. The rationale for this model is that early intervention is likely to be associated with a better response to treatment. 


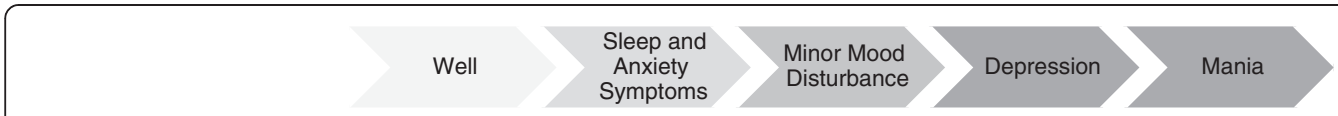

Fig. 1 Course of prodromal symptoms in bipolar disorder

In the same vein, Kapczinski et al. presented a staging model that emphasizes the assessment of patients in the inter-episodic period and includes the following: latent phase-individuals who present mood and anxiety symptoms and increased risk for developing threshold bipolar disorder; stage I-patients with bipolar disorder who present well-established periods of euthymia and absence of overt psychiatric morbidity between episodes; stage II-patients who present rapid cycling or current axis I or II comorbidities; stage III-patients who present a clinically relevant pattern of cognitive and functioning deterioration, as well as altered biomarkers; and stage IV-patients who are unable to live autonomously and present altered brain scans and biomarkers (Kapczinski et al. 2009). The progression across these presentations may be engendered by the cumulative exposure to acute episodes, drug abuse, life stress, and inherited vulnerability (Kapczinski et al. 2009). As a corollary of these early descriptions, the notion of functional staging emerged in the field of bipolar disorder. Functional staging may provide a practical model to guide therapy to improve quality of life. In this regard, a strong linear association was reported between The Functioning Assessment Short Test (FAST) scores and the clinical stages described by Kapczinski (Kapczinski et al. 2009), suggesting a progressive functional decline from stage I through stage IV of bipolar disorder (Rosa et al. 2014). Similarly, by applying latent class analysis in a sample of 106 remitted adults with bipolar disorder, one study identified two subtypes of patients presenting "good" and "poor" functional outcomes (Reinares et al. 2013). Estimated verbal intelligence, inhibitory control, episode density, and level of residual depressive symptoms emerged as the most significant predictors of each subtype (Reinares et al. 2013). Of note, functional outcome was not predicted by illness duration, since the two groups were comparable in age, age of onset, and illness duration (Reinares et al. 2013).

Moreover, a recent task force of the International Society for Bipolar Disorders has performed a systematic review

Table 1 Neuroimaging findings and staging models of bipolar disorder

\begin{tabular}{ll}
\hline $\begin{array}{l}\text { Clinical } \\
\text { staging }\end{array}$ & Clinical presentation \\
\hline 0 & Increased risk of bipolar disorder; no symptoms currently
\end{tabular}

Neuroimaging findings

Resilience markers: abnormal prefrontal cortical activity increases during cognitive control of emotion and cognitive control tasks; abnormal volumetric increases in right-sided vIPFC and left-sided subcortical regions

Risk markers: abnormally increased amygdala activity; abnormal prefrontal WM

$1 \quad$ a) Mild or nonspecific symptoms

b) Ultra-high-risk: moderate but subthreshold symptoms, with neurocognitive changes and functional decline to caseness

$2 \quad$ First episode of bipolar disorder; full threshold disorder with moderate to severe symptoms, neurocognitive deficits, and functional decline

3 a) Incomplete remission from first episode (could be linked or fast-tracked to stage 4)

b) Recurrence or relapse of psychotic or mood disorder which stabilizes with treatment, residual symptoms, or neurocognition Resilience markers: Abnormally increased prefrontal cortical activity during cognitive control of emotion and cognitive control tasks; abnormally increased prefrontal cortical volume

Risk markers: abnormally decreased prefrontal cortical volumes; left-sided subcortical volume increases; abnormally decreased WM volume

Emotion processing: abnormally decreased prefrontal cortical activity (especially right-sided vIPFC activity) during cognitive control of emotion and cognitive control tasks; abnormally increased amygdala activity during these tasks; abnormally decreased prefrontal cortical volumes and decreased prefrontal WM; altered subcortical volumes

Reward processing: abnormally increased left-sided striatal and prefrontal cortical activity during reward processing

Markers of disease progression: a negative association between prefrontal cortical volumes (especially right vIPFC gray matter volume) and illness duration; reductions in amygdala, striatal, and hippocampal volumes with illness progression 
on staging models for bipolar disorders (Kapczinski et al. 2014). It showed that available data converge to suggest that broadly defining bipolar disorder as early and late stage is heuristically useful (Kapczinski et al. 2014). Also, the review has shown a proposal for functional neuroimaging findings according staging in 2014 (Frank et al. 2014). The structural changes were categorized in two themes: emotion processing and reward processing (Frank et al. 2014). Resilience and risk markers for individuals at risk and markers of disease progression for patients with bipolar disorder were also stated in the study (Table 1).

In conclusion, the current paper (Keown-Stoneman et al. 2015) and the previous studies of Duffy and colleagues have created a heuristic model for staging prodromal phases of bipolar disorder. This added to the notion that bipolar disorder may be conceived in terms of differential stages (Duffy et al. 2010). Of note, we need to use the specific evidence pertaining to $\mathrm{BD}$ from longitudinal studies of high-risk individuals and patients to develop a comprehensive specific staging model for BD. The opportunity to characterize transitions to full-blown illness and developmental staging models is the first step to paradigm shifts in preventative strategies. Recent progress in molecular psychiatry and the use of multiscale datasets coupled with machine learning techniques may help to refine predictive models of conversion to bipolar disorder in clinical and population samples (Kapczinski and Passos 2015).

\section{Competing interests}

The authors declare that they have no competing interest.

\section{Authors' contributions}

ICP drafted the manuscript and participated in the literature search and tables. KJ participated in the literature search and figure. FK drafted the manuscript and participated in the literature search and tables. All authors read and approved the final manuscript.

\section{Acknowledgements}

ICP is supported by scholarship from CAPES, Brazil. FK is supported by CNPq, Brazil.

\section{Author details}

${ }^{1}$ UT Center of Excellence on Mood Disorder, Department of Psychiatry and Behavioral Sciences, The University of Texas Science Center at Houston, 1941 East Road, Houston, TX 77054, USA. Bipolar Disorder Program and Laboratory of Molecular Psychiatry, Federal University of Rio Grande do Sul, Porto Alegre, RS, Brazil. ${ }^{3}$ Health and Behavior Program, Catholic University of Pelotas, Pelotas, RS, Brazil.

Received: 18 June 2015 Accepted: 21 July 2015

Published online: 31 July 2015

\section{References}

Berk M, Conus P, Lucas N, Hallam K, Malhi GS, Dodd S, et al. Setting the stage: from prodrome to treatment resistance in bipolar disorder. Bipolar Disord. 2007;9:671-8. doi:10.1111/j.1399-5618.2007.00484.x.

Duffy A, Alda M, Hajek T, Sherry SB, Grof P. Early stages in the development of bipolar disorder. J Affect Disord. 2010;121:127-35. doi:10.1016/ j.jad.2009.05.022.
Frank E, Nimgaonkar VL, Phillips ML, Kupfer DJ. All the world's a (clinical) stage: rethinking bipolar disorder from a longitudinal perspective. Mol Psychiatry. 2014. doi:10.1038/mp.2014.71.

Kapczinski F, Dias W, Kauer-Sant'Anna M, Frey BN, Grassi-Oliveira R, Colom F, et al. Clinical implications of a staging model for bipolar disorders. Expert Rev Neurother. 2009;9:957-66. doi:10.1586/ern.09.31.

Kapczinski F, Magalhães PVS, Balanzá-Martinez V, Dias W, Frangou S, Gama CS, et al. Staging systems in bipolar disorder: an International Society for Bipolar Disorders Task Force report. Acta Psychiatr Scand. 2014;130:354-63. doi:10.1111/acps.12305.

Kapczinski F, Passos IC. Wet minds, dry minds, and the future of psychiatry as a science. Acta Psychiatr Scand. 2015;131:7-8. doi:10.1111/acps.12357.

Keown-Stoneman CD, Horrocks J, Darlington GA, Goodday S, Grof P, Duffy A. Multi-state models for investigating possible stages leading to bipolar disorder. Int J Bipolar Disord. 2015;3:5. doi:10.1186/s40345-014-0019-4.

Lapalme M, Hodgins S, LaRoche C. Children of parents with bipolar disorder: a metaanalysis of risk for mental disorders. Can J Psychiatry. 1997;42:623-31.

Reinares M, Papachristou E, Harvey P, Mar Bonnín C, Sánchez-Moreno J, Torrent C, et al. Towards a clinical staging for bipolar disorder: defining patient subtypes based on functional outcome. J Affect Disord. 2013;144:65-71. doi:10.1016/j.jad.2012.06.005.

Rice J, Reich T, Andreasen NC, Endicott J, Van Eerdewegh M, Fishman R, et al. The familial transmission of bipolar illness. Arch Gen Psychiatry. 1987:44:441-7.

Rosa AR, Magalhães PVS, Czepielewski L, Sulzbach MV, Goi PD, Vieta E, et al. Clinical staging in bipolar disorder: focus on cognition and functioning. J Clin Psychiatry. 2014;75:e450-6. doi:10.4088/JCP.13m08625.

Scott J, Paykel E, Morriss R, Bentall R, Kinderman P, Johnson T, et al. Cognitive-behavioural therapy for severe and recurrent bipolar disorders: randomised controlled trial. Br J Psychiatry. 2006;188:313-20. doi:10.1192/bjp.188.4.313.

Swann AC, Bowden CL, Calabrese JR, Dilsaver SC, Morris DD. Differential effect of number of previous episodes of affective disorder on response to lithium or divalproex in acute mania. Am J Psychiatry. 1999;156:1264-6.

\section{Submit your manuscript to a SpringerOpen ${ }^{\circ}$ journal and benefit from:}

- Convenient online submission

Rigorous peer review

- Immediate publication on acceptance

- Open access: articles freely available online

- High visibility within the field

- Retaining the copyright to your article

Submit your next manuscript at springeropen.com 